\title{
Documento porque ficciono, ficciono porque documento: a ressignificação de imagens de arquivo no cinema brasileiro contemporâneo
}

Documentary on fiction, fiction on documentary: the archival footage resignification in the new Brazilian

cinema

Marcelo Dídimo Souza Vieira Correio

Doutor em Multimeios pela UNICAMP, Professor Adjunto do Instituto de Cultura e Arte da

Universidade Federal do Ceará

Resumo: No cinema brasileiro recente, o diálogo entre o documentário e a ficção tem merecido destaque, com produçôes de baixo orçamento e ideias originais. É o caso de Santiago (João Moreira Salles, 2007) e Viajo Porque Preciso, Volto Porque Te Amo (Marcelo Gomes, Karim Aïnouz, 2009), filmes que trabalham esse diálogo de forma sutil e diegética, ressignificando imagens de um arquivo próprio, pessoal.

Palavras chave: Documentário; Ficção; Ressignificaçáo

Abstract: In recent Brazilian cinema, the dialogue between documentary and fiction has been highlighted, with low budget productions and original ideas. This is the case of Santiago (João Moreira Salles, 2007) and Viajo Porque Preciso, Volto Porque Te Amo (Marcelo Gomes, Karim Ainouz, 2009), films that converge this dialogue in a diegetic and subtle way, resignifying images from a personal archive Keywords: Documentary; Fiction; Resignification 


\section{Introdução}

O diálogo entre a ficção e o documentário nos filmes não é próprio do cinema contemporâneo. No entanto, nas últimas décadas, realizadores do Brasil e do exterior tem transitado por esses pólos e várias obras audiovisuais têm ganhado destaque por manterem um diálogo aberto e diegético entre a ficção e o documentário, deixando cada vez menos nítida a fronteira que separa essas duas linguagens.

A partir da década de 2000, algumas obras audiovisuais têm sido realizadas com a preocupação de manter esse diálogo entre a ficção e o documentário de forma mais contundente, em que as linguagens se sobrepóem e, por vezes, não é possível fazer a distinção entre um e outro.

\footnotetext{
$\mathrm{Na}$ medida em que um rico diálogo se estabelece entre o regime de criação ficcional e os procedimentos documentais, volta ao debate essa clássica distinção entre os dois modos como o cinema se relaciona com o mundo fora das telas. Por isso não é exagero destacar esse diálogo como um dos traços mais marcantes do cinema brasileiro contemporâneo. (MATTOS, 2011, p. 1)
}

No Brasil, alguns filmes de baixo orçamento e sem grandes bilheterias, mas com ideias ousadas e que trabalham esse diálogo entre as duas linguagens de forma bastante original, têm merecido destaque no meio cinematográfico, dos quais é possível citar: Serras da Desordem (Andrea Tonacci, 2006); Santiago (João Moreira Salles, 2007); Jogo de Cena (Eduardo Coutinho, 2007); Moscou (Eduardo Coutinho, 2009); Juizo (Maria Augusta Ramos, 2008); Morro do Céu (Gustavo Spolidori, 2009); Filmefobia (Kiko Goiffman, 2009); e Viajo Porque Preciso, Volto Porque Te Amo (Marcelo Gomes, Karim Aïnouz, 2009); dentre outros.

Dentre os filmes citados, Santiago e Viajo Porque Preciso, Volto Porque Te Amo têm um diferencial, o uso de imagens de arquivo em sua narrativa. Essas imagens, no entanto, não se referem aos arquivos que estamos acostumados a ver nos filmes, de telejornais ou películas antigas, mas de um arquivo próprio, um acervo pessoal de imagens dos realizadores, que seráo revisitadas posteriormente e, consequentemente, ressignificadas.

João Moreira Salles decupou com extrema precisão o seu projeto de documentário sobre o antigo mordomo que trabalhava na sua casa, repetindo os planos exaustivamente até a perfeição, o que acabou transformando o produto final (não finalizado) em uma história ficcional, tal era o nível de direcionamento que Santiago recebia, perdendo a naturalidade que advém do primeiro registro. Ao retomar o projeto, anos depois, o realizador entrou em crise, pois ficou claro que deixou de lado o que deveria ser prioritário: o que o imigrante apaixonado pelas nobrezas e dinastias queria falar, mostrar, 
revelar. O resultado dessa crise é uma forte autocrítica sobre a produção do documentário e a manipulação das imagens.

Já no filme de Marcelo Gomes e Karim Aïnouz, o processo estrutural é inverso, embora o ponto de partida seja o mesmo. Os realizadores tinham a intenção original de fazer um filme sobre o sertão e captaram diversas horas de imagens documentais numa incursão realizada pelo interior do Nordeste. Quando retomaram o projeto e começaram a fazer a seleção das imagens, concluíram que elas tinham emoção suficiente para construir uma narrativa dramática e passaram a buscar uma forma de costurá-las para tal. Daí surge o personagem narrador, que faz a mesma incursão dos diretores pelo sertão - claro, as imagens são o resultado dessa viagem.

Esta quebra de intencionalidade - a intenção no momento da filmagem versus a intenção no momento de montagem - instaura uma nova natureza à função do(s) realizador(es) dentro do filme. É dessa forma que se torna interessante pensar nos filmes em questáo como fruto de uma inventividade específica, uma possibilidade dentre várias, mas que não se desprende da instância do real, tendo em mente o pressuposto de que ambos estão situados nesse lugar de encontro entre o documentário e a ficção.

\section{Documentário e ficção}

Antes de apontar possíveis semelhanças ou oposiçôes entre os conceitos de ficção e documentário, é importante perceber que a relação estabelecida entre ambos os termos não é óbvia. Sua suposta oposição não está explicitada desde sempre; o cinema não nasce essencialmente dividido entre a realidade ou a invenção - ainda que esse recorte também seja possível nos primeiros anos da existência do cinematógrafo. As operações que nos permitem denominar determinado grupo de filmes como ficcionais enquanto outros ganham a classificação de documentais se construiu pelo tempo, pelos movimentos. As tentativas de definiçóes nascem a partir das idas e vindas estéticas, das articulações de ideias nos discursos fílmicos, das proposiçôes diferenciadas de regimes imagéticos, da produção de filmes e textos pura e simplesmente, e principalmente, da iniciativa de pessoas que se propuseram a pensar sobre a produção cinematográfica.

Bill Nichols inicia sua reflexão sobre o campo do documentário com a seguinte proposição: “Todo filme é um documentário" (2005, p. 26). $\mathrm{O}$ autor parte do pressuposto de que todos os filmes, mesmo aqueles tidos como ficçôes, documentam, registram e revelam características de um mundo real e histórico; o cinema atua a partir de e em direção a esse mundo físico, compartilhado por todos nós, que faz parte de uma noçáo vinculada ao conceito de realidade. O cinema parece manter vínculos com tal realidade mesmo quando sua intenção não é reproduzi-la enquanto tal; 
mas o conceito de realidade mantém-se como referencial para a fabulação de novos mundos ou novos pontos de vista sobre os mesmos mundos. É partindo desse pensamento que Nichols propóe uma nova definição para os termos ficção e documentário: seriam os documentários de satisfação de desejos e os documentários de representação social.

Os documentários de satisfação de desejos abrangeriam o que comumente se chama de ficção: seriam os filmes que estão mais ligados à lógica da imaginação, da construção de universos e personagens sem o compromisso com a realidade, da busca pela invençáo.

Expressam aquilo que desejamos, ou tememos, que a realidade seja ou possa vir a ser. Tais filmes transmitem verdades, se assim quisermos. São filmes cujas verdades, cujas ideias e pontos de vista podemos adotar como nossos ou rejeitar. Oferecem-nos mundos a serem explorados e contemplados; ou podemos simplesmente nos deliciar com o prazer de passar do mundo que nos cerca para esses outros mundos de possibilidades infinitas. (NICHOLS, 2005, p. 26)

Já os documentários de representação social seriam, segundo Nichols, aqueles relacionados ao que já se chama de não-ficção ou documentário:

\footnotetext{
Tornam visível e audível, de maneira distinta, a matéria de que é feita a realidade social, de acordo com a seleção e a organização realizadas pelo cineasta. (...) Esses filmes também transmitem verdades, se assim quisermos. Precisamos avaliar suas reivindicaçóes e afirmaçóes, seus pontos de vista e argumentos relativos ao mundo como o conhecemos, e decidir se merecem que acreditemos neles. Os documentários de representação social proporcionam novas visóes de um mundo comum, para que as exploremos e compreendamos. (NICHOLS, 2005, p. 26-27)
}

É interessante perceber que os termos realidade, verdade e pontos de vista aparecem em ambas as definiçóes, reforçando a ideia de que o cinema mantém vínculos estritos com a realidade, independente das estratégias estéticas e narrativas que adote. Todavia, Nichols chama a atenção para o fato de que os filmes que integram cada categoria se relacionam de formas diferentes com os elementos de realidade, verdade ou mundo. Sáo filmes que, apesar de, em última instância, documentarem os desejos de uma época - ou de um lugar, um grupo ou mesmo um indivíduo -, acabam por construir maneiras diferentes de relacionar cinema e vida; os filmes ditos ficcionais exigem do espectador uma postura diferente dos filmes documentais, por exemplo. 
Outro ponto de vista é teorizado por Jaques Aumont, que parece partir de uma premissa contrária, mas não contraditória a de Nichols, para elaborar o conceito de que "qualquer filme é um filme de ficção" (AUMONT, 1995, p. 100). Aumont se baseia no fato de que o cinema, por si só, é constituído por elementos que estão ausentes na hora da projeção, ou seja, na hora em que o filme concretiza sua função. As imagens e sons projetados nada mais são do que registros - resquícios, sombras - dos reais objetos e manifestações físicas, diferentemente do teatro, por exemplo, em que as pessoas e os objetos representados de fato existem e se fazem presentes no momento da apresentação. A ausência de tais elementos na projeção faria de todo dispositivo cinematográfico um ato ficcional, pois o cinema lidaria diretamente com imagens-restos do real e, portanto, passíveis de manipulaçóes e escolhas estéticas. "O filme de ficção é, portanto, duas vezes irreal: irreal pelo que representa (a ficção) e pelo modo como representa (imagens de objetos ou de atores)" (AUMONT, 1995, p. 100).

Para complementar sua linha de raciocínio, Aumont também recorre às teorias da semiótica ao afirmar que "qualquer objeto já é signo de outra coisa, já está preso em um imaginário social e oferece-se, então, como o suporte de uma pequena ficção" (AUMONT, 1995, p. 101). Para o autor, o real parece ser inacessível em sua completude, e qualquer tentativa de apreendê-lo passa pelo processo de invenção e de escolhas, em que tanto os realizadores dos filmes quanto os espectadores das obras submetem a dita realidade às suas próprias questóes e vivências. Daí sua denominação de "pequenas ficções".

Esse embate entre os dois teóricos, longe de se mostrar contraditório, reforça ainda mais a ideia de que os termos ficção e documentário não dizem respeito apenas a características estéticas propostas pelos filmes, mas se organizam como uma grande rede de relações, conceitos e ideias que balizam a produção e a percepção desses filmes perante o mundo. Entender as implicaçóes que o campo da ficção ou do documentário levantam vai além de conhecer suas principais características manifestas, mas também entender como esses filmes conseguem estabelecer vínculos com seu público e com a vida e que efeitos tais vínculos levantam. Um filme pode ser ficção sob um ponto de vista, mas também documentário sob outro, e o que está em jogo não é sua verdadeira classificação, mas sim o desdobramento das múltiplas relaçóes que o filme pode tecer.

É nesse sentido que é possível afirmar que as fronteiras entre as linguagens de ficção e documentário são ao mesmo tempo claras e complexas. Claras porque se apóiam em estruturas já pré-definidas e pré-indicadas, de relativa fácil assimilação; estruturas estas que são responsáveis por construir lugares de produção e apreensão seguros, em que as regras já estáo dadas e que permite que realizador/ espectador reconheça em determinado regime cinematográfico a maneira como deve se relacionar com ele. Por outro lado, são complexas porque tais estruturas não podem ser definidas completamente em última análise: as "exceçóes" fazem 
parte das próprias regras, e as apropriaçóes de linguagem que um campo incide sobre o outro vai enriquecendo as relaçóes possíveis entre eles, assim como entre espectador e cinema.

Quando essas barreiras são minimamente rompidas, quando por alguns instantes o risco alcança tais lugares seguros, quando as certezas parecem oscilar, o diálogo entre ficção e documentário acaba exigindo de seu público e de seus produtores novas posturas frente às imagens. Somos intimados a correr o mesmo risco que os personagens dos filmes, simplesmente porque náo temos mais a garantia de que todos saíram imunes (emocional ou fisicamente) do processo de filmagem. Ao mesmo tempo, também somos intimados a assumir o risco de que possíveis transformaçóes vislumbradas em tela podem ter ocorrido apenas em tela, num processo de fabulação que não deixa de dialogar com a realidade.

\section{Imagem de arquivo e subjetividade}

Quando se fala em imagem de arquivo, remete-se, num primeiro momento, a filmes que utilizam imagens antigas para compor a obra atual, sejam imagens televisivas ou de filmes passados. Geralmente estão relacionados a documentários históricos ou filmes de ficção que trabalham com reconstituições de histórias passadas. Nesse sentido, a imagem de arquivo acaba se tornando um documento, um recurso audiovisual que irá corroborar, reforçar o que a obra atual está abordando.

\footnotetext{
O interesse pelo arquivo tem vários efeitos sobre o contexto artístico atual: a atenção renovada pelo documento é um deles. Acreditamos que certa visão da história tem muito a nos ensinar sobre a questão do documento. (...) O documento, em muitos trabalhos artísticos, não é, em absoluto, algo objetivo e inocente que "expressa uma verdade" sobre uma determinada época, mas aquilo que expressa, consciente ou inconsciente, "o poder da sociedade do passado sobre a memória e o futuro" (LE GOFF, 1990, p. 6). (LINS, REZENDE e FRANÇA, 2011, p. 58)
}

Quando bem utilizado, esse documento audiovisual pode, e deve, trazer à nova obra um valor inestimável de pesquisa, refletindo a busca do realizador por um material que estava arquivado e, por vezes, esquecido. Geralmente, essas imagens foram captadas "em diferentes mídias e provenientes de variadas fontes: arquivos públicos, privados, familiares, pesso $\neg$ ais, cinematográficos, televisivos, de vigilância etc." (LINS, REZENDE e FRANÇA, 2011, p. 57).

Normalmente, trabalha-se com arquivos de terceiros, públicos ou privados, em que se exige uma negociação para utilizar essas imagens. Às vezes essa negociação pode ser demorada, burocrática e com regras de uso, quando não se tem que pagar pequenas fortunas para conseguir seus direitos. Mas em determinados momentos, essas fontes são "pessoais", segundo os autores supracitados, portanto, não existe a apropriação de imagens de terceiros, pois são imagens próprias dos realizadores, de 
um acervo pessoal de imagens, um banco de dados audiovisual que pode ser revisitado, reutilizado e, quando for o caso, ressignificado.

Aqui, o objetivo é entender que o conceito a que se referem as imagens de arquivo pode atingir uma amplitude mais próxima do realizador, e que esse arquivo pode ser próprio, e não de outrem. Dessa forma, não existe negociação, burocracia e, principalmente, custos financeiros para os direitos autorais. Eduardo Coutinho abriu seu baú 20 anos após as filmagens do Cabra Marcado original para realizar sua obra final no início da década de 1980, só para lembrar uma das referências mais significativas do cinema brasileiro.

Da mesma forma o fez João Moreira Salles.

Santiago nasceu da tentativa de João Moreira Salles, realizada em 1992, de produzir um filme sobre o mordomo de sua antiga casa. Essa premissa já traz em seu âmago o viés saudosista e, até mesmo, intimista do projeto. Seria por meio do melhor criado de sua residência que o diretor teria acesso às lembranças de sua própria história. Porém, no processo de edição, o material bruto que Salles havia filmado se mostrou ineficaz para o projeto pensado inicialmente. O Santiago que ele dirigiu, cuja personalidade se empenhou tanto para construir na frente das câmeras, talvez não fosse o Santiago que quisesse presente no filme. Essa foi a razão pela qual Salles abandonou o projeto indefinidamente. Treze anos depois, retomou o projeto. Esse retorno ao material, no entanto, produziu uma crise no diretor, como é possível perceber na própria película. Santiago deixa de ser um filme focado no personagem que habitava a mente de João, correspondente ao seu antigo mordomo, para introduzir novas discussóes que, ao mesmo tempo em que aprofundam, extrapolam as lembranças da família Salles.

Neste processo de re-produção, Salles descobre que deixou de lado o que era mais importante, o que o personagem queria falar, mostrar. Santiago, o imigrante apaixonado pelas nobrezas e dinastias. O narrador fala da falta de planos próximos e admite que aquela distância representava a própria distância entre diretor e personagem, que aquilo deixava por vezes Santiago desconfortável e que ia além da relação diretor-personagem, pois era ainda uma relação patrão-empregado. Já era tarde para fazer novas imagens com Santiago, tendo o argentino falecido poucos anos após as gravaçôes, então, em um dos poucos registros factuais da direção de documentários, João Moreira Salles expóe justamente a repetição de tomadas, as coordenadas de olhar, de posicionamento, de fio condutor, além do próprio tratamento carregado de uma hierarquia que, anos depois, continuava presente entre realizador e personagem, ao descobrir que ali residia a real espontaneidade daquele projeto.

Através da presença do que normalmente é eliminado na montagem de um filme, reconhecemos os pontos que perturbam Salles hoje; a direção das falas, textos e gestos e o excesso de zelo estético na composição dos quadros e no trabalho da fotografia. (MIGLIORIN, 2007, p. 5) 
Este zelo também causa incômodo no diretor. Ao não se recordar perfeitamente do momento de realização das tomadas e do que foi propositalmente arranjado nos quadros, o narrador (o eu-lírico de João), ao revisitar os planos da casa vazia, percebe e adverte para o espectador: "Tudo deve ser visto com certa desconfiança”. Ao fazer essa advertência, João expõe, além da aspereza por trás das câmeras, a própria tensão presente na película, essa fronteira entre o documentário e a ficção. Explicita-se, a partir de então, o abismo que separa o real das imagens que presenciamos. Assim como a memória de Santiago, os planos podem ser fabricados, ou posados, de modo que, da mesma forma que o diretor não tem mais acesso a Santiago, nem a sua infância na residência da Gávea, os espectadores também não alcançaráo o momento captado dessas imagens.

Esse arranjo que Santiago promove entre as possíveis intençôes e visíveis manipulaçóes existentes no momento da produçáo de imagens, se aproxima de uma discussão sobre os arquivos audiovisuais, trazendo à tona a ideia do documento como monumento, ou seja, do documento náo mais como registro factual de um acontecimento, mas como a própria expressão de um tempo, costume ou sociedade.

\footnotetext{
O documento é monumento porque resulta de um esforço das sociedades que o guardaram e manipularam para 'impor ao futuro determinada imagem de si próprias' (LE GOFF, 1990, p. 538) (...) Qualquer documento, por ser monumento, é, ao mesmo tempo, verdadeiro e falso, na medida em que esconde/revela traços das condiçóes em que foi produzido e do poder que o produziu. (LINS, REZENDE e FRANÇA, 2011, p. 60 e 61)
}

Assim, ao evidenciar o material bruto que teria ficado de fora da obra final, João Moreira Salles desconstrói a ideia de documento como sinônimo de verdade - e é interessante pensar em como a imagem, talvez mais do que o texto ou a própria oralidade, pode adquirir uma natureza comprobatória (de documento) com imensa aderência, algo que é colocado em cheque e evidenciado no filme. As imagens de arquivo, nesse caso, contribuem para que seja alcançada uma memória imediata, possível de ser mediada pelo encontro câmera-personagem-diretor, e não uma memória plena, implacável e inabalável. O filme, portanto, não descarta o lugar da memória e do passado como possibilidades de se falar do mundo e das pessoas, náo atribui a eles um caráter de inutilidade e de total desvencilhamento do mundo, mas os reconfigura dentro de um cenário onde a própria realidade é fruto de processos e escolhas.

Salles expõe também as suas próprias conclusôes tiradas a partir desse retorno ao material bruto, percepções tanto existenciais quanto artísticas. Surge a identificação do diretor com Santiago. O filme é, "acima de tudo, a narrativa perturbadora e comovente de um aprendizado e de uma transformação de um cineasta no confronto com ele mesmo em um outro momento da vida” (LINS e MESQUITA, 2008, p. 78). 
Karim Aïnouz e Marcelo Gomes foram um pouco mais longe, pois foi com o material registrado no sertão nordestino que eles realizaram Sertão de Acrílico Azul Piscina, em 2004, participaram da exposição O Cinema dos Pequenos Gestos (Des) Narrativos, em 2011, e realizaram Viajo Porque Preciso, Volto Porque Te Amo, em 2009. Nesse filme, percebemos que o processo estrutural é inverso, embora o ponto de partida seja o mesmo: a ressignificação de um material bruto com finalidade inicial divergente do resultado final. Karim Aïnouz e Marcelo Gomes tinham a intenção original de produzir um documentário sobre o sertâo brasileiro. Segundo Gomes:

A gente queria falar sobre essas encruzilhadas de modernidade e passado que tem o sertão. (...) Então mudou essa ideia de fazer um filme sobre essa relação de passado e presente no sertão, apesar de isso estar presente no filme. A gente decidiu guardar as imagens como se guardasse num baú e depois de muito tempo fomos rever as imagens. (GOMES apud MAHMOUD, 2009, p. 3)

Quando os realizadores retomam o projeto e começam a fazer a seleção das imagens, percebem que podem articulá-las de forma tal a construir uma narrativa muito bem delineada. Daí surge o personagem José Renato, um geólogo que percorre o mesmo caminho de descobertas que Karim e Marcelo fizeram. $\mathrm{O}$ personagem fala de um amor que, a princípio, parece fazer parte de seu presente, ao mesmo tempo em que vai registrando o que vê pela estrada, criando, assim, uma trajetória que se modifica o tempo todo, conforme a sua relação com o ambiente e com as pessoas. Adquire, assim, uma intimidade e uma percepção diferentes, já que passam a atingi-lo de forma heterogênea.

Para os realizadores, essa construção posterior do filme se deu a partir de processos, de buscas por ambientes e personagens ideais, cujos registros imagéticos conservam um olhar quase descompromissado com a formação de um discurso. As imagens, em suas diferentes texturas e formas de interceder no real, possuem uma força própria justamente por estarem livres de imposições de verdades. Registram a paisagem em movimento, as estradas vazias ou perpassadas por caminhóes, o céu azul ou estourado, os singelos gestos dos moradores locais, etc. São imagens livres, desprendidas, autônomas. Imagens que são movidas pelo fio condutor de uma busca maior, que não se materializa ali, concretamente, e nem se define especificamente, mas que motiva os olhares afetuosos da câmera em relação às pessoas, aos espaços e aos objetos que interpela.

Uma imagem de arquivo é uma imagem indecifrável e sem sentido enquanto não for trabalhada na montagem. Fotografias ou imagens em movimento dizem muito pouco antes de serem montadas, antes de serem colocadas em relação com outros elementos — outras imagens e temporalidades, outros textos e depoimentos. Segundo Didi-Huberman, ou se pede demais da imagem, que ela represente o Todo, a verdade inteira 
- o que é impossível, pois elas serão sempre inexatas, inadequadas, lacunares, ou se pede muito pouco, desqualificando-a, sob a acusação de que não passa de simulacro, excluindo-a, portanto, do campo da história e conhecimento (DIDI-HUBERMAN, 2003, p. 85 apud LINS, REZENDE e FRANÇA, 2011, p. 57).

É nesse entre-lugar que Viajo Porque Preciso... se articula. No filme, as imagens nem tentam dar conta do todo, nem se desligam completamente dele. Ganham sentido justamente pela costura proposta. A narrativa que envolve o filme e a montagem que pressupóe uma serialização dos elementos vão encaixando, pouco a pouco, cada plano num contexto particular. Os caminhóes que passam pelas estradas podem transportar tanto pessoas que fogem de amor como motoristas que buscam o posto de gasolina mais próximo para abastecer o tanque. A indefinição factual de tais imagens torna possível divagar sobre elas, (re)inventar seus sentidos.

No filme, o que está em jogo não é questionar a veracidade que tais imagens possam adquirir, mas sim ressaltar as possibilidades de apreensão das mesmas. A camada do real e da ficção estão o tempo inteiro em tensão, pois não se busca mais o alcance do real, ou mesmo sua negação. A instância narrativa que conduz o filme dá pouca importância a qualquer sedimentação do filme no âmbito da verdade, preferindo se articular a partir de retratos e sensaçóes fugidias que nascem a partir dos personagens encontrados pela viagem, dos lugares visitados, nas paradas feitas em bares de beira de estrada, hotéis e pousadas, festejos religiosos, festas, boates, circos, monumentos ou lagos. $\mathrm{O}$ mais importante para a construção do filme não são as imagens em si, mas o sentido que se dá a elas. Sentido este que está presente tanto numa instância ficcional como na documental.

Outro ponto em comum entre os dois filmes é o fato de ambos tornarem explícita a presença de uma subjetividade - que deriva dos próprios realizadores, mas que está longe de dar conta deles - dentro do próprio filme. O que estamos chamando de subjetividades (para evitar possíveis complicaçóes desnecessárias) são presenças fílmicas que vão interagir de alguma forma com os objetos, personagens e lugares com os quais as imagens se deparam, e que possuem uma certa individualidade, características próprias que balizam a forma como essa interação se dá, bem como os caminhos que o filme perpassa. A narração e a voz off/over são importantes elementos na configuração dessa subjetividade, mas veremos que tais presenças fílmicas não se resumem a elas.

No caso de Santiago, o primeiro elemento a ser analisado é o texto proferido pela voz over. A narração do personagem João Moreira Salles dá conta de dividir o pesar que o realizador sente com relação ao projeto e às imagens originais, além de confidenciar conversas que não foram registradas e orientar a montagem do filme. Joáo Moreira Salles está o tempo inteiro lembrando e apontando ao espectador como o filme teria sido se tivesse sido 
finalizado treze anos atrás, ao mesmo tempo em que revela as fraquezas e as imprudências - na sua opinião - do projeto inicial. Deixa claro, portanto, que o processo de se fazer o filme é também um processo de autocrítica, de se debruçar sobre o mesmo material com um olhar diferenciado, buscando outras questôes a serem desenvolvidas e apontando as inúmeras contradiçóes existentes anteriormente. Assim, Santiago acaba se tornando um filme sobre outro filme que nunca existiu e nem vai existir, um resquício de outro resquício.

A voz over que enuncia o texto choca-se com a voz off do diretor in loco, no momento das filmagens, principalmente quando Joáo Moreira Salles dá orientaçôes a Santiago as quais ele mesmo iria desqualificar alguns anos depois. São dois diretores, dois discursos diferentes. Isso é ainda mais claro quando percebemos que a voz over não é proferida por João, mas sim por seu irmáo Fernando Moreira Salles, que assume o papel do irmáo ao recitar o texto em primeira pessoa. Santiago, trabalha questóes de modo bastante autocrítico, mas enunciado por outra pessoa que não é seu realizador de fato, a quem essa autocrítica se refere. Essa estratégia ressalta ainda mais o entrelaço entre ficção e documentário, transformando a presença de João Moreira Salles - tão inflamada de um discurso externo a todo procedimento fílmico, em última instância - em apenas mais um personagem do filme.

De qualquer forma, é essa presença-personagem que conduz a projeção, que reconstrói através da montagem os momentos previstos no projeto inicial - como, por exemplo, a abertura do filme - e que faz questão de explicitar que tais momentos pertencem ao filme anterior, não ao filme presente. É por isso que dizemos que essa presença não se dá apenas pela voz em si, mas pela própria concatenação dos planos e pelo discurso que se cria a partir disso. Apesar de a narração constituir-se em um fator essencial à narrativa do filme, Santiago traz momentos que destoam do caminho de resgate de imagens do filme. Um destes instantes é composto por uma cena registrada em super- 8 , arquivo de família, com o diretor ainda criança e os demais Salles na piscina da casa onde Santiago os serviu por trinta anos. A cena é silenciosa, e até mesmo a música e a narração são interrompidas nesse momento, marcando o ápice da exposição que João Moreira Salles faz de si no filme. Além dessa imagem extremamente íntima, encontramos também planos monocromáticos, puramente sensórios, que funcionam não como um hiato, mas exatamente como um modo de apoio da relação entre documentário e ficção. Ora o plano é acidental (causado pelo desgaste da película), ora é proposital, causando assim uma quebra harmoniosa na montagem do filme.

Enquanto o personagem/diretor tem o objetivo de ser descoberto, escutado e compreendido pelo público, José Renato, o protagonista de Viajo Porque Preciso, Volto Porque Te Amo, estabelece outras relaçóes com o espectador e com o filme. A voz over/off acaba se tornando a representante 
do segmento ficcional da obra e o meio de expressão direto de José Renato. É uma busca completamente pragmática que inicialmente move o personagem, interessado na natureza das rochas e do solo do interior do Nordeste. Nesse momento, sua voz adquire características de um registro de trabalho, quase uma catalogação do seu percurso e descobertas, relacionando-se com um suposto interlocutor burocrático, aquele ao qual ele deve satisfaçóes de seu serviço prestado. Entretanto, aos poucos, a força da vida pessoal de José Renato vai se manifestando no próprio discurso falado do personagem. Primeiro timidamente, quando ele diz: "Por que insistem em fazer essa obra aqui? Na verdade isso não é problema meu. Tô com fome”. É a quebra de um discurso que antes apenas se preocupava em descrever as condiçóes do solo. São justamente essas pequenas inserçôes que revelam pouco a pouco os anseios de José Renato. Descobrimos - ou melhor, percebemos, já que nada nos é informado concretamente sobre o que aconteceu - que o geólogo sente uma falta imensa de sua "galega", como a chama. Percebemos, pelos seus comentários, que os dois estão separados, em crise, por algum motivo que não interessa.

A voz de José Renato, então, em última instância, é a responsável por construir a fábula e a trama da ficção, fazendo referência ao que aconteceu com o personagem antes da viagem acontecer e às condiçóes nas quais a viagem é feita. É responsável também por conduzir a montagem e o ritmo das imagens, instaurando outra camada de compreensão às imagens vistas, já que elas agora fazem parte de um todo, trocam significados com a narrativa estabelecida e passam pelo crivo do olhar de José Renato. Apesar disso, a voz ainda assim possui um caráter de indefinição. Que origem tem ela? Por vezes se comporta como um registro de trabalho, algo apontado anteriormente. Mas, em outras, parece se dirigir diretamente à galega de quem o protagonista sente falta, como se ela pudesse ouvi-lo, como na frase: "Não aguento mais tentar te esquecer". Há, também, a voz que se configura como expressáo direta dos pensamentos de José Renato, como se ele simplesmente pensasse alto: "Não quero que essa viagem acabe nunca".

Dessa forma, imagem e som (voz) empreendem a mesma busca, ainda que por caminhos diferentes: cada um constrói através de sua própria natureza uma força autônoma. As imagens não esgotam seus significados apenas no âmbito da narrativa, vão além da subordinação a uma dramaturgia, estabelecendo-se atuante no registro dos gestos que elas mesmas se propóem a cuidadosamente observar. Da mesma forma, a voz procura se tornar manifestante de um estado de espírito, uma atmosfera de um personagem, sem estar presa à materialidade da imagem ou ao aspecto visual e concreto que esta última inevitavelmente impóe. As estradas, as pessoas e os lugares não atuam como ilustraçóes do real narrativo, mas como representantes de um recorte feito diretamente na própria realidade. 
A quebra mais acentuada dessa construção é sem dúvida na cena em que José Renato conversa com Paty. Esse momento insere-se na lógica e no formato da entrevista, em que Paty, enquadrada em um plano fixo observacional, apenas responde perguntas feitas por uma voz off (que, na verdade, é over). Essa voz, que muito provavelmente pertencia anteriormente a Karim ou a Marcelo, é substituída pela voz de Irandhir Santos, ou seja, José Renato, apontando para uma ideia não apenas de entrevista, mas também de diálogo, de conversa entre os dois personagens. Ficção e documentário tornam-se unos através de uma entrevista/ dialogo.

Enfim, ao projetarem uma subjetividade articuladora dentro da própria obra, ambos os filmes criam elementos de mediação para com as imagens de arquivo, que operam no sentido de construir narrativas, universos e discursos, trazendo à tona novamente as discussóes entre os campos do documentário e da ficção.

\section{Considerações finais}

É por meio desses instantes sutis, do plano monocromático à narrativa extrapolada através da entrevista e do diálogo, de um arquivo pessoal de imagens ressignificadas posteriormente, que estes filmes rompem a divisão genérica entre documentário e ficção, e nesse hibridismo ensaístico, questôes outrora taxativas resultam em reflexões acerca do poder de criação da imagem.

\footnotetext{
Tal qual um gênero híbrido e moderno, entre a filosofia e a arte, entre a precisão conceitual e a busca por um estilo livre e pessoal, o ensaio se volta contra o imediatismo para estabelecer mediaçóes, preferindo sempre o parcial, o inconcluso e o fragmentário. Isto é, preferindo aquilo que escapa ao pensamento sistemático, totalizante e dogmático - aquilo que escapa, portanto, às definiçóes conceituais e às deduçóes definitivas. (FELDMAN in MIGLIORIN, 2010, p. 150)
}

Os realizadores propóem, assim, novas possibilidades de utilização da imagem. Além disso, os diretores fazem uma espécie de crítica ao modelo tradicional de documentário, “à prova de erros”. João Moreira Salles descobre e assume em seu filme que essa forma tradicional é um modelo no qual ele suscita questóes acerca da produção cinematográfica e que, de agora em diante, terá uma nova leitura.

[João Moreira Salles] sabe o que é um documentário. Este saber mudou, suas crenças na imagem e no controle sobre elas se transformaram (...). Neste sentido, o filme aparece como uma síntese desse saber que se transformou. (MIGLIORIN, 2007, p. 2) 
De fato, os realizadores que trabalham com documentário têm transformado seu modo de pensar o filme e criado novas possibilidades, novos caminhos, explorando a criatividade no desenvolvimento de suas obras, deixando para o público e para os novos realizadores referências de estilos os mais diversos, abrindo um leque de opções para quem quer experimentar sem se prender a uma teoria de gênero. A linha que tem separado o documentário da ficção vem ficando muito sensível e pode ser quebrada de vez em quando, dando espaço a possibilidades infinitas de criação para atender não só a um público cada vez mais plural, mas à própria diversidade entre os realizadores, que não precisam mais fazer escolhas taxativas de gênero.

\section{Referências bibliográficas}

AUMONT, Jaques. et al. A estética do filme. Campinas, SP: Papirus, 1995. LINS, Consuelo; REZENDE, Luiz Augusto; FRANÇA, Andréa. A noção de documento e a apropriação de imagens de arquivo no documentário ensaístico contemporâneo. Revista Galáxia, São Paulo, n. 21, p. 57, jun. 2011.

LINS, Consuelo; MESQUITA, Cláudia. Filmar o real: sobre o documentário brasileiro contemporâneo. Rio de Janeiro: Jorge Zahar Ed., 2008.

MAHMOUD, Laila Abou. Entrevista com Marcelo Gomes. Revista Bravo! Online, 2009. Disponível em: http://bravonline.abril.com.br/materia/viajo-porque-preciso-volto-porque-te-amo-jornada-poetica-geografia-adentro. Acessado em 16 de setembro de 2012.

MATTOS, Carlos Alberto. Doc $+f i c$ : a era do híbrido, 2011. Disponível em: http://carmattos.com/2011/02/25/doc-fic-a-era-do-hibrido. Acessado em 19 de maio de 2012.

MIGLIORIN, Cezar (org.). Ensaios no real: o documentário brasileiro hoje. Rio de Janeiro, RJ: Beco do Azougue, 2010.

. Entre o saber e a experiência. Revista Cinética, 2007. Disponível em: http://www.revistacinetica.com.br/santiagocezar.htm. Acessado em 30 de outubro de 2012.

NICHOLS, Bill. Introdução ao documentário. Campinas, SP: Papirus, 2005. 